\title{
A qualitative motion analysis study of voluntary hand movement induced by music in patients with Rett syndrome
}

This article was published in the following Dove Press journal:

Neuropsychiatric Disease and Treatment

I October 2009

Number of times this article has been viewed

\author{
Tohshin Go' \\ Asako Mitani ${ }^{2}$ \\ 'Center for Baby Science, Doshisha \\ University, Kizugawa, Kyoto, Japan; \\ ${ }^{2}$ Independent Music Therapist (Poco A \\ Poco Music Room), Tokyo, Japan
}

\begin{abstract}
Patients with Rett syndrome are known to respond well to music irrespective of their physical and verbal disabilities. Therefore, the relationship between auditory rhythm and their behavior was investigated employing a two-dimensional motion analysis system. Ten female patients aged from three to 17 years were included. When music with a simple regular rhythm started, body rocking appeared automatically in a back and forth direction in all four patients who showed the same rocking motion as their stereotyped movement. Through this body rocking, voluntary movement of the hand increased gradually, and finally became sufficient to beat a tambourine. However, the induction of body rocking by music was not observed in the other six patients who did not show stereotyped body rocking in a back and forth direction When the music stopped suddenly, voluntary movement of the hand disappeared. When the music changed from a simple regular rhythm to a continuous tone without an auditory rhythm, the periodic movement of both the hand and body prolonged. Auditory rhythm shows a close relationship with body movement and facilitates synchronized body movement. This mechanism was demonstrated to be preserved in some patients with Rett syndrome, and stimulation with music could be utilized for their rehabilitation.
\end{abstract}

Keywords: Rett syndrome, music, auditory rhythm, stereotyped movement, body rocking, voluntary movement

\section{Introduction}

Rett syndrome is a childhood neurodevelopmental disorder usually caused by a mutation in the gene encoding MECP2 located on the X chromosome (Xq28). ${ }^{1}$ Rett syndrome occurs predominately in females although males have been described with MECP-2 mutations. ${ }^{2}$ Stereotyped movement of the hands such as wringing, washing, hand clapping, and hand-to-mouth movements following the loss of the functional use of the hands is the most characteristic feature of Rett syndrome. ${ }^{3}$ Typically, patients with Rett syndrome have no verbal skills, and about $50 \%$ of them are not ambulatory. ${ }^{3}$ However, they are reported to respond well to music in comparison with their physical and verbal disabilities. ${ }^{4-7}$

Synchronized movement to music has been observed in all known human cultures, implying that this ability is universal and perhaps unique to human musical behavior. ${ }^{8}$ Among various musical elements such as pitch, melody, harmony, rhythm, dynamics, timbre, etc., auditory rhythm is known to exhibit a close and fundamental relationship with body movement from early infancy, ${ }^{9,10}$ and facilitates synchronized body movement not only in healthy subjects of all ages but also in patients with various movement disorders such as Parkinson disease, ${ }^{11}$ Huntington's disease, ${ }^{12}$ stroke, ${ }^{13}$ and 
incomplete spinal cord injury. ${ }^{14}$ Improvement in walking speed and stride length by auditory rhythm was demonstrated in patients with Parkinson disease. ${ }^{15,16}$ These findings suggest that auditory rhythm could also modify motor behavior and induce voluntary movement in patients with Rett syndrome; however, little is known about the basic role of auditory rhythm in these patients. ${ }^{17}$

The motion analysis system is a well established clinical method to examine temporal, spatial, and kinetic movements of various parts of the human body, particularly for the assessment of gait in healthy subjects ${ }^{18}$ and intervention evaluation in patients with cerebral palsy. ${ }^{19}$ We utilized this method to investigate the relationship between auditory rhythm and behavioral movement in patients with Rett syndrome in order to promote their voluntary hand movement.

\section{Patients and methods}

Ten female patients with Rett syndrome, aged from three to 17 years, were included in this study. The diagnosis was made by more than two child neurologists according to the diagnostic criteria for Rett syndrome established by the Rett Syndrome Diagnostic Criteria Work Group. ${ }^{20}$ Patient profiles are described in Table 1. All patients showed stereotyped hand movement. In addition, eight of 10 patients had stereotyped body rocking movement: back and forth, three; left and right, four; and both, one (Table 1).

According to the previous study on motion analysis in a patient with Rett syndrome, ${ }^{21}$ markers were put on the wrists and shoulders in patients to investigate the movement of their hands and upper bodies, respectively. Color tapes 20-mm wide were employed as the markers, and their movements were captured using a two-dimensional digital video camera at a sampling frequency of $30 \mathrm{~Hz}$. Two-dimensional motion analysis software (Move-Tr/2D ver.7; Library Co., Ltd., Japan) was utilized to record temporal, spatial, and kinetic changes of movements in response to music in a qualitative manner.

First, a tambourine was presented in front of patients for several seconds. When no purposeful movement was observed, music familiar to each patient related to us by caregivers was started with a simple regular rhythm. Sometimes, the music was stopped suddenly or changed from a simple regular rhythm to a continuous tone without any rhythm to assess any behavioral changes in movement. This examination was performed after music therapy for six months. Each session was 40 minutes long and was provided once or twice a month.

This study was approved by the Institutional Ethics and Research Board, and informed written consent was obtained from legally authorized representatives of the patients. Participants were outpatients of Saitama General and Medical Center for the Disabled.

\section{Results}

When music with a simple regular rhythm started, body rocking appeared automatically in a back and forth direction in all four patients who had the same body movement as their stereotyped movement (Table 1). Through this body rocking induced by music, voluntary hand movement increased gradually and finally became sufficient to beat a tambourine presented in front of the patient (Table 1). This voluntary hand movement was observed consistently during and after the study when patients were awake and in a good temper. However, the induction of body rocking by music was not

Table I Profiles of patients and movement induced by music

\begin{tabular}{|c|c|c|c|c|c|c|c|}
\hline Age & Gene & EEG & Sz & Physical ability & $\begin{array}{l}\text { Stereotyped } \\
\text { body movement }\end{array}$ & $\begin{array}{l}\text { Induced body } \\
\text { rocking }\end{array}$ & $\begin{array}{l}\text { Induced hand } \\
\text { movement }\end{array}$ \\
\hline 3 & $A b$ & $\mathrm{~N}$ & - & Ambulatory & Left and right & - & - \\
\hline 4 & $A b$ & $A b$ & - & Sitting & Left and right & - & - \\
\hline 4 & $\mathrm{Ab}$ & $\mathrm{N}$ & + & Sitting & Left and right & - & - \\
\hline 5 & ND & $\mathrm{Ab}$ & + & Ambulatory & None & - & - \\
\hline 6 & $A b$ & $A b$ & - & Wheelchair & Back and forth & + & + \\
\hline 7 & $A b$ & $A b$ & + & Ambulatory & Back and forth & + & + \\
\hline 9 & ND & $A b$ & + & Sitting & Left and right & - & - \\
\hline 11 & $\mathrm{Ab}$ & $A b$ & + & Ambulatory & $\begin{array}{l}\text { Back and forth } \\
\text { Left and right }\end{array}$ & + & + \\
\hline 12 & $A b$ & $A b$ & + & Crawling & Back and forth & + & + \\
\hline 17 & ND & $\mathrm{Ab}$ & - & Wheelchair & None & - & - \\
\hline
\end{tabular}

Abbreviations: EEG, electroencephalogram; Sz, seizure; Ab, abnormal; N, normal; ND, not done; Wheelchair, impossible to maintain any posture without assistance. 
observed in the other six patients who did not have stereotyped body rocking in a back and forth direction (Table 1).

The motion analysis system demonstrated that body rocking induced by music consisted of primarily repetitive horizontal back and forth movement and little vertical movement (Figure 1). It persisted with almost the same regular periodic cycle as the auditory rhythm of music and constant amplitude while the music continued (Figure 1). Through this regular and cyclic body movement induced by music, voluntary hand movement gradually increased in a vertical direction with the same periodic cycle as the body, and finally allowed the patient to reach the tambourine presented in front of her (Figure 1). Vertical movement of the hand was much more pronounced than horizontal movement of the body (Figures 1-3).

When the music stopped suddenly, voluntary movement of the hand soon disappeared (Figure 2). Horizontal movement of the body also decreased gradually and stopped after a while (Figure 2). Horizontal movement of the hand merely reflected the accompanying motion of the body in the same direction. When the music changed from a simple regular rhythm to a continuous tone without an auditory rhythm, movements of both the hand and body became slower and the periodic cycle of the motion prolonged (Figure 3).

\section{Discussion}

In this study, patients with Rett syndrome showing stereotyped body rocking in a back and forth direction were demonstrated to recognize and respond well to changes in the rhythm of music. A simple regular auditory rhythm induced stereotyped body rocking movement in a back and forth direction at first. Then, the auditory rhythm as well as induced body rocking movement facilitated voluntary movement of the hands.

Purposeful hand movement was performed through this regular and cyclic body movement induced by music. The target object was placed in front of patients and patients watched it. This might explain why only stereotyped body rocking in a back and forth direction was induced in this study.

Stereotyped movement is repetitive, restricted, and nonfunctional motor behavior observed in various neurological and developmental disorders such as Rett syndrome, ${ }^{3}$ autistic disorder, ${ }^{22}$ and visual or auditory impairment. ${ }^{23}$ If it is frequent and severe, it may interfere with normal voluntary movement. Therefore, treatment and rehabilitation usually focuses on how to suppress it in order to facilitate voluntary movement. However, voluntary movement can be induced more easily through using rather than suppressing stereotyped movement in patients whose voluntary movement is very difficult to promote, such as those with Rett syndrome. The reinforcement of rhythm in stereotyped movement by music might be another way of rehabilitation for such patients. ${ }^{17}$

Action induction by music is accompanied by neural impulses in the reticular formation of the brainstem. ${ }^{24}$ In addition, listening to a simple regular rhythm without

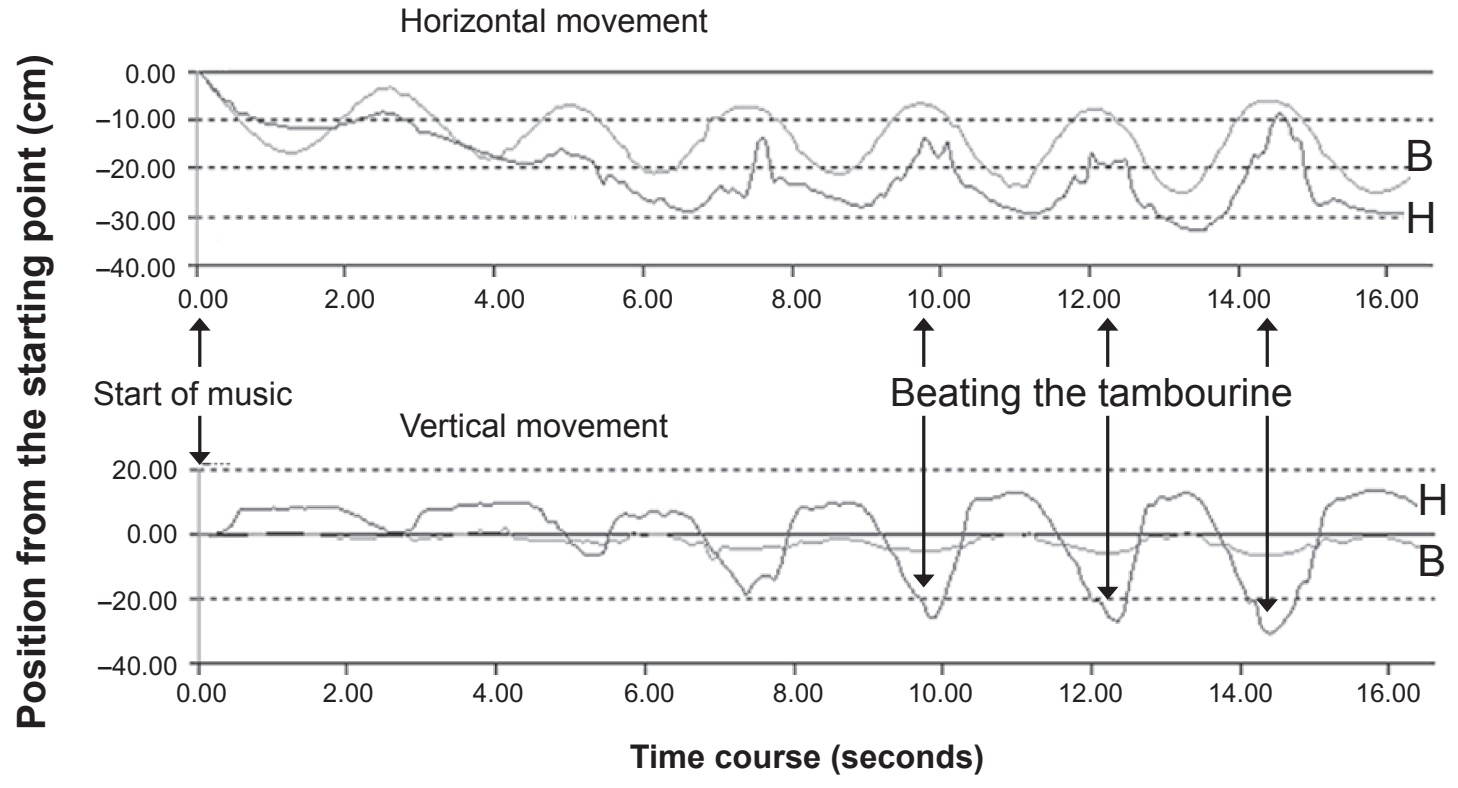

Figure I Motion analysis of an I I-year-old patient.

Notes: The horizontal axis is the time course and the vertical axis is the position from the starting point of each body part. Forward and upward positions from the starting point are shown as positive values. Movements of the body and hand are indicated by lines B and H, respectively. 


\section{Horizontal movement}

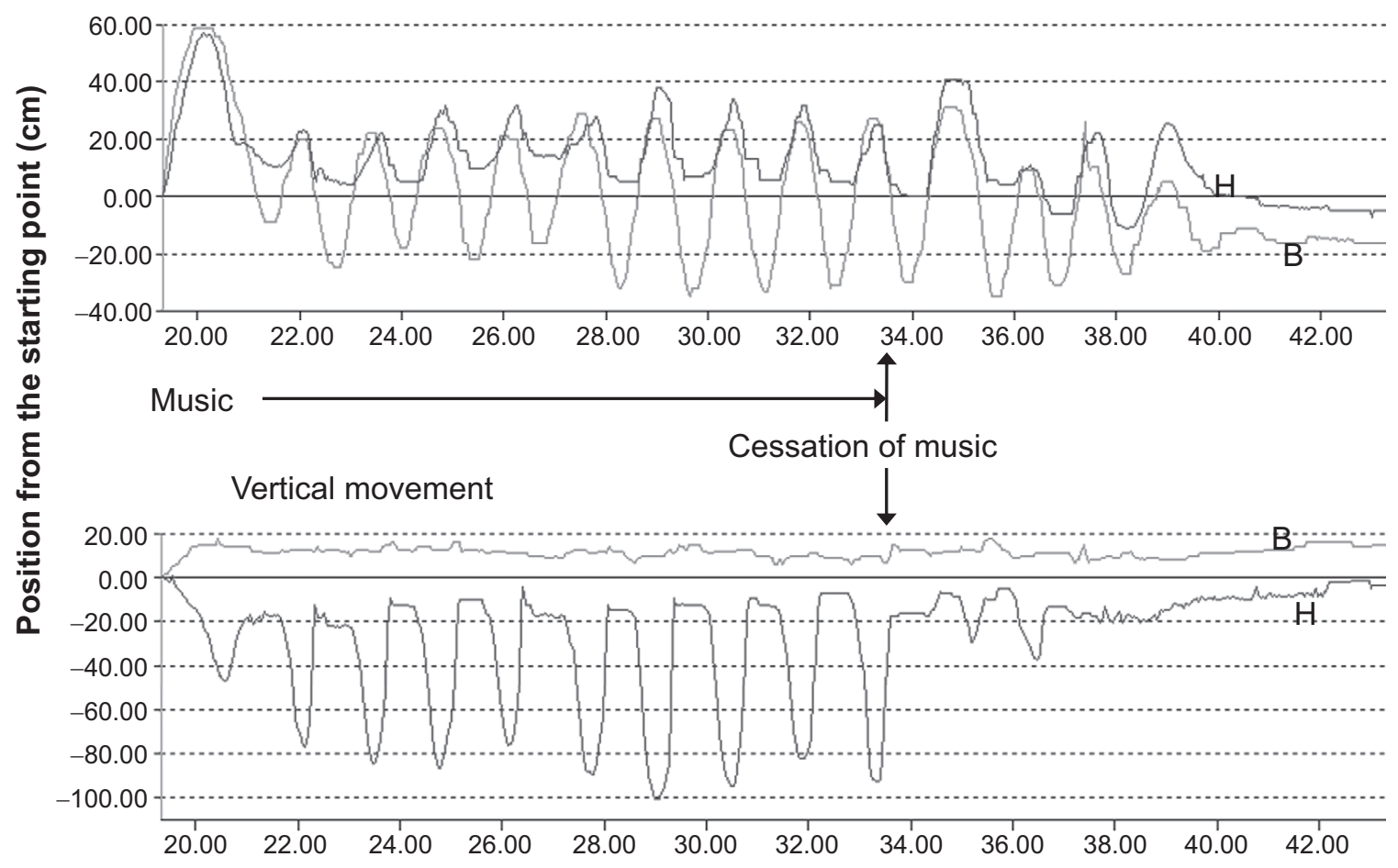

Time course (seconds)

Figure 2 Changes in motion by the abrupt cessation of music in a 7-year-old patient. Note: Axes and symbols are the same as in Figure I.

\section{Horizontal movement}

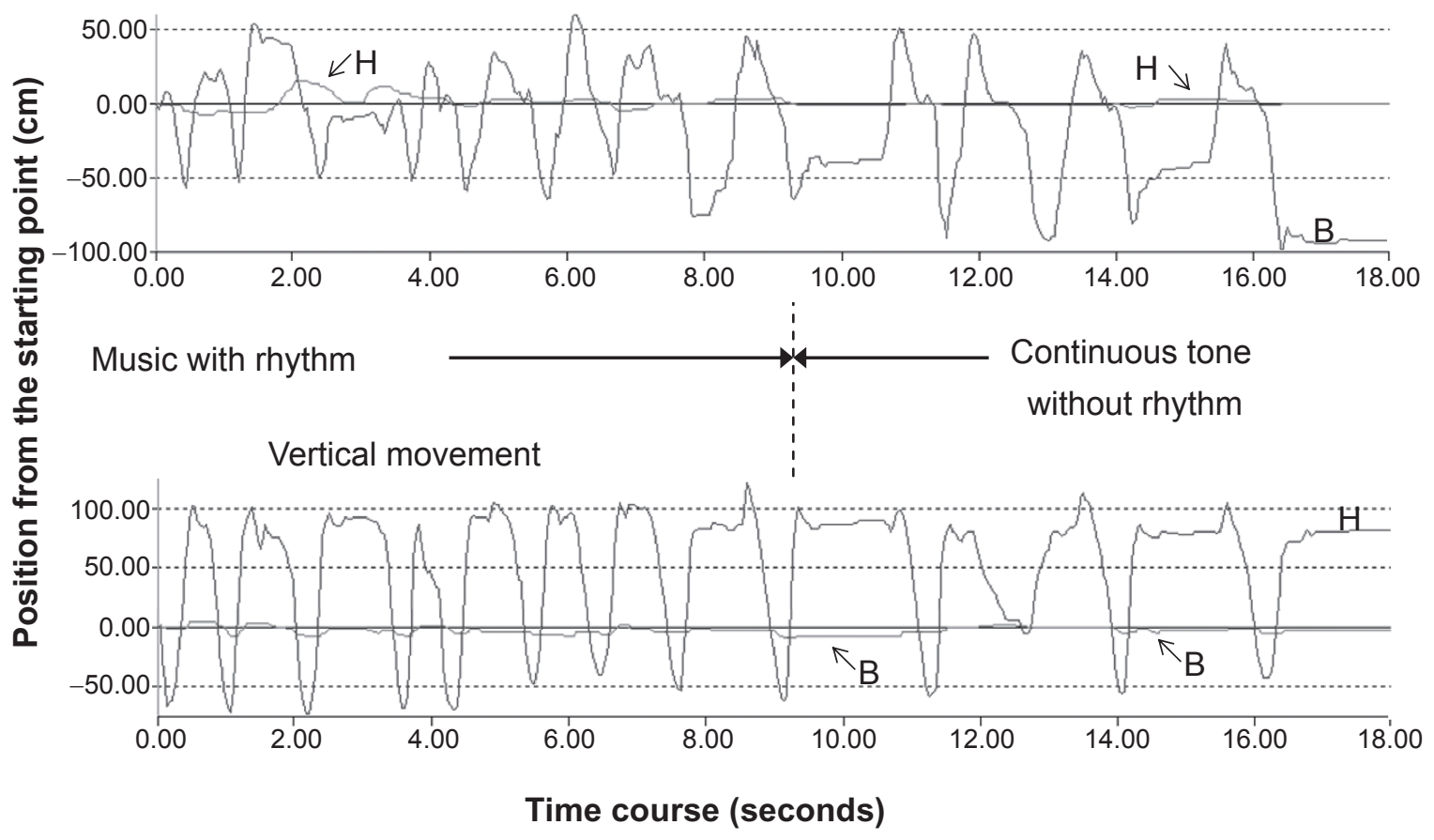

Figure 3 Changes in motion induced by music with and without a rhythm in a I2-year-old patient. Note: Axes and symbols are the same as in Figure I. 
any actual movement increases the activity of the basal ganglia and supplementary motor area. ${ }^{9}$ These brain areas are involved in motor prediction and the timing of future movements..$^{25,26}$ Therefore, listening to music with a simple regular rhythm would prime body movement. This mechanism could be preserved in some patients with Rett syndrome, and stimulation with music might be worth attempting for their rehabilitation. Actually, patients who responded to music showed some improvement of their hand use in everyday life such as opening the door or holding an object for a while even though Rett syndrome progresses with gradual deterioration of the motor system.

In this study, the movement of 10 patients was analyzed in a qualitative manner without a control group. Further studies involving more subjects including older patients with a control group are necessary to clarify the role of auditory rhythm in patients with Rett syndrome.

\section{Acknowledgements}

This study was supported in part by The Japan Health Foundation. The authors report no conflicts of interest in this work.

\section{References}

1. Smeets EE, Chenault M, Curfs LM, Schrander-Stumpel CT, Frijns JP. Rett syndrome and long-term disorder profile. Am J Med Genet A. 2009;149A(2):199-205.

2. Jülich K, Horn D, Burfeind P, Erler T, Auber B. A novel MECP2 mutation in a boy with neonatal encephalopathy and facial dysmorphism. J Pediatr. 2009;155(1):140-143.

3. Matijevic T, Knezevic J, Slavica M, Pavelic J. Rett syndrome: from the gene to the disease. Eur Neurol. 2009;61(1):3-10.

4. Kerr AM, Archer HL, Evans JC, Prescott RJ, Gibbon F. People with MECP2 mutation-positive Rett disorder who converse. I Intellect Disabil Res. 2006;50(Pt5):386-394.

5. Wesecky A. Music therapy for children with Rett syndrome. Am J Med Genet Suppl. 1986;1:253-257.

6. Yasuhara A, Sugiyama Y. Music therapy for children with Rett syndrome. Brain Dev. 2001;23(Suppl 1):S82-S84.

7. Wigram T, Lawrence M. Music therapy as a tool for assessing hand use and communicativeness in children with Rett Syndrome. Brain Dev. 2005;27(Suppl 1):S95-S96.

8. Brown S. Biomusicology, and three biological paradoxes about music. Bull Psychol Arts. 2003;4:15-17.
9. Grahn JA, Brett M. Rhythm and beat perception in motor areas of the brain. J Cogn Neurosci. 2007;19(5):893-906.

10. Zatorre RJ, Chen JL, Penhune VB. When the brain plays music: auditory-motor interaction in music perception and production. Nat Rev Neurosci. 2007;8(7):547-558.

11. McIntosh GC, Brown SH, Rice RR, Thaut MH. Rhythmic auditorymotor facilitation of gait patterns in patients with Parkinson's disease. J Neurol Neurosurg Psychiatry. 1997;62(1):22-26.

12. Thaut MH, Miltner R, Lange HW, Hurt CP, Hoemberg V. Velocity modulation and rhythmic synchronization of gait in Huntington's disease. Mov Disord. 1999;14(5):808-819.

13. Thaut MH, Leins AK, Rice RR, et al. Rhythmic auditory stimulation improves gait more than NDT/Bobath training in near-ambulatory patients early poststroke: a single-blind randomized trial. Neurorehabil Neural Repair. 2007;21(5):455-459.

14. de 1'Etoile SK. The effect of rhythmic auditory stimulation on the gait parameters of patients with incomplete spinal cord injury: an exploratory pilot study. Int J Rehabil Res. 2008;31(2):155-157.

15. Lim I, van Wegen E, de Goede C, et al. Effects of external rhythmical cueing on gait in patients with Parkinson's disease: a systematic review. Clin Rehabil. 2005;19(7):695-713.

16. Satoh M, Kuzuhara S. Training in mental singing while walking improves gait disturbance in Parkinson's disease patients. Eur Neurol. 2008;60(5):237-243.

17. Go T. Medical music therapy based on Baby Science (baby-science-based music therapy) and assistive technology for children. Curr Pediatr Rev. 2007;3(3):198-206.

18. Chester VL, Tingley M, Biden EN. Comparison of two normative paediatric gait databases. Dyn Med. 2007;6:8.

19. Westwell M, Ounpuu S, DeLuca P. Effects of orthopedic intervention in adolescents and young adults with cerebral palsy. Gait Posture. 2009;30(2):201-206.

20. Diagnostic criteria for Rett syndrome. The Rett Syndrome Diagnostic Criteria Work Group. Ann Neurol. 1988;23(4):425-428.

21. Wright M, van der Linden ML, Kerr AM, Burford B, Arrowsmith G, Middleton RL. Motion analysis of stereotyped hand movements in Rett syndrome. J Intellect Disabil Res. 2003;47(Pt 2):85-89.

22. Goldman S, Wang C, Salgado MW, Greene PE, Kim M, Rapin I. Motor stereotypies in children with autism and other developmental disorders. Dev Med Child Neurol. 2009;51(1):30-38.

23. Gal E, Dyck MJ, Passmore A. The relationship between stereotyped movements and self-injurious behavior in children with developmental disabilities. Res Dev Disabil. 2009;30(2):342-352.

24. Molinari M, Leggio MG, De Martin M, Cerasa A, Thaut M. Neurobiology of rhythmic motor entrainment. Ann N Y Acad Sci. 2003;999: 313-321.

25. Sardo P, Ravel S, Legallet E, Apicella P. Influence of the predicted time of stimuli eliciting movements on responses of tonically active neurons in the monkey striatum. Eur J Neurosci. 2000;12(5):1801-1816.

26. Rao SM, Harrington DL, Haaland KY, Bobholz JA, Cox RW, Binder JR. Distributed neural systems underlying the timing of movements. J Neurosci. 1997;17(14):5528-5535.
Neuropsychiatric Disease and Treatment

\section{Publish your work in this journal}

Neuropsychiatric Disease and Treatment is an international, peerreviewed journal of clinical therapeutics and pharmacology focusing on concise rapid reporting of clinical or pre-clinical studies on a range of neuropsychiatric and neurological disorders. This journal is indexed on PubMed Central, the 'PsycINFO' database and CAS, and is the official

\section{Dovepress}

journal of The International Neuropsychiatric Association (INA). The manuscript management system is completely online and includes a very quick and fair peer-review system, which is all easy to use. Visit http://www.dovepress.com/testimonials.php to read real quotes from published authors. 